\title{
The Impact of Industry Commonality on Post-merger Performance
}

\author{
Hsuan-Chu Lin ${ }^{1, *}$, Yi-Yun Chou ${ }^{2}$ \\ ${ }^{1}$ Department of Accounting and Graduate Institute of Finance and Banking, National Cheng Kung University, Taiwan \\ ${ }^{2}$ Graduate Institute of Finance and Banking, National Cheng Kung University, Taiwan
}

Copyright $\bigcirc 2016$ by authors, all rights reserved. Authors agree that this article remains permanently open access under the terms of the Creative Commons Attribution License 4.0 International License

\begin{abstract}
The purpose of this paper is to identify the impact of industry commonality on post-merger performance and further examine whether the acquiring firms have the abnormal returns after mergers and acquisitions which is evidenced by many prior studies. Through the US sample of 3016 observations consisting of 1732 related and 1284 unrelated acquisitions from 1995 to 2009 , we find that the abnormal returns of acquisitions during three years are all negative, but the post-performances of related acquisitions is significantly better than those of unrelated acquisitions. Moreover, while insignificant in the first year, the related acquisitions have significantly positive impact on market performances in the second and third years.
\end{abstract}

Keywords Industry Commonality, Merger and Acquisition, Post-merger Underperformance

JEL: G34; L2; L16

\section{Introduction}

Being able to respond to the global competition, companies need to expand their business and take up challenges. There are two methods for enterprises to choose, internal development and mergers and acquisitions (M\&A). Enterprise enhances its economic scale and keeps the competitive strength by M\&A. Synergy, the most basic motivation of M\&A, occurs if the value of the combined firm after the merger is greater than the sum of the value the acquiring firm and the value of the acquired firm before the merger.

There are five waves in the history of M\&A which originated from the United States. In the 19th century, the first peak period of mergers and acquisition, approximately 75 percent of U.S. companies disappeared due to M\&A. Large enterprises rapidly increased their market shares and monopolized in all walks of life. In the early 20th century, enterprises began to adopt the vertical merger. A vertical merger is the one in which a firm combines with a supplier or a distributor to form a trust organization. The main markets of industrial countries were generally monopolized by few enterprises. In the $1950 \mathrm{~s}$, the major industrial countries began the third M\&A wave. Major developed countries have carried out a large-scale investment in fixed assets. The size and speed of this wave are more than two previous ones. In the fourth waves, the scale of M\&A is much bigger than before, and financial industries played an important role. Enterprises mainly used the leverage buyout and expanded business to abroad. In the beginning of the 1990s, cross-border M\&A became the main way of foreign direct investment due to the economic globalization. Foreign direct investment is direct investment into production in a country by a company located in another country, either by buying a company in the target country or by expanding operations of an existing business in that country.

In order to confirm the increase of firm value rather than the useless expanding, it is important to observe the performance of firm after M\&A. In relevant theories, we can find that many factors which can affect the post-merger performance. According to Kusewitt(1985), Healy, Palepu, and Ruback(1992), Markides and Ittner (1994) and Linn and Switzer (2001), all of them took industry commonality into account but the result is entirely different.

In the general M\&A theory, it argues that diversification cannot produce increases in value. A business's variability of return can be separated into two parts, unsystematic and systematic. Systematic variability cannot be eliminated by diversification, so mergers will not eliminate this at all. Unsystematic can be diversified away, but investors can diversify more easily rather than firms. The risk of firms which implement industry diversification by mergers is higher than investors who change their portfolios. However, some empirical theories have the different views. Ghosh (2001) though that the unrelated acquisitions can increase more the operating cash flow of acquiring firms.

Under the relevant theories, there is no consistent conclusion between the industry commonality and 
performance. For example, Healy (1992) and Switzer (1996) consider the performance of related acquisitions is better than unrelated. However, Linn and Switzer (2001) propose that there is no positive relation between the industry commonality of mergers and acquisitions and the long-term performance. Huang (2009), the study in Taiwan also indicates that whether the industry-related M\&A can bring more benefits to acquiring firms is not significant. Some of these results violate the general theory which firms can obtain the maximum benefit if they focus on their original business and put all resources in one field. Due to this inconsistent result, we am interested in exploring whether the industry commonality is positively correlated with the performance. Since M\&A is the main method which firms adopt to expand business, it is worth to identify the relationship between industry commonality and post-merger performance.

This paper contributes to the related empirical M\&A literature in the followings. Using 3016 acquisitions from 1995 to 2009 and two methods to calculate the post-merger performances over three years, our results support the general findings of most prior studies by showing show that both related and unrelated acquisitions have negative abnormal return after merger completion. More importantly, the significantly positive relationship between industry commonality and post-merger performance found in this study especially contain important implications for both investors and the management. That is, industry commonality does affect the severity of corporate post-merger underperformance and therefore the firm value. As for investors, when a firm adopts the unrelated acquisitions, they might adjust their investment portfolios to avoid the potential losses. As for the managers of companies, they should do more evaluations and consider other factors before doing unrelated acquisitions since most of them may harm the value of firms.

The remaining of this paper is organized as follow. In section two, we would review the relevant literatures on the performance of M\&A, diversification, and factors that could influence firm performance. Section three presents the data selection and methodology which are used in this paper. In Section four, we would provide the outcome on empiric and analyzes the results. Section five makes the conclusion.

\section{Literature Review}

\section{Performance of Mergers and Acquisitions}

The performance of M\&A is a principal issue in recent studies. Many previous studies discuss and categorize it into two parts, pre-acquisition and post-acquisition. Pre-acquisition mainly focuses on the selection process which could bring in the synergy. Post-acquisition is the implementation stage of the acquisition process of organizational fit.
Recently, scholars have increasingly begun to focus on factors influencing the management of post-acquisition relationships as potentially critical in acquisition success or failure. Seth (1990) reviews theoretical and empirical issues regarding synergistic benefits of acquisitions, empirically tests propositions regarding gains associated with different acquisition strategies, and argues that value creation necessarily depends on the combination of characteristics of the two merging firms rather than those of each of the firms considered alone. In this paper, we mainly focus on the firm performance after fit and measures how much value M\&A could bring to the acquiring firms. Therefore, it is important to analyze how to measure the performance of M\&A and what factors can affect it.

Many previous studies examine different measures of M\&A performance. Kusewitt (1985) uses the regression analysis which dependent variables are two measures of the financial performance, accounting return on assets (ROA) and market return. Relative size, acquisition rate, asset acquisition rate, industry commonality, acquisition timing, type consideration, targets profitability, and price paid are independent variables. Fowler and Schmidt (1989) explore the relationships between commonly discussed strategic acquisition factors and long-term financial performance measures of acquiring firms. The financial performance measures include both accounting and capital market data. The factors of interest include relative size, previous acquisition experience, organizational age, industry commonality, contested versus uncontested acquisitions, and percentage of stock acquired. Agrawal and Mandelker (1992) use the cumulative average abnormal return to examine the post-merger performance of acquiring firms. Healy, Palepu and Ruback (1992) examine post-acquisition performance for the 50 largest U.S. mergers between 1979 and mid-1984. Merged firms show significant improvements in asset productivity relative to their industries, leading to higher operating cash flow returns. Bruton, Oviatt and White (1994) use one dichotomous explanatory variable (business commonality), three continuous explanatory variables (acquisition experience, relative firm sizes, and relative firm sizes squared), and one continuous control variable (change in the net income of the target) to predict acquisition performance.

Ooghe and Balcaen (2000) provide ten indicators about the performance of mergers including the current ratio, operating margin, ROE, ROA, cash flow/capital, stockholders equity/ total asset, cash flow/ total debt, cash and short-term invest/ current asset, per margin, and marginal personnel expenditures. Walker (2000) uses the regression model to test the determinants of acquiring-firm shareholder wealth, cumulative market-adjusted return, and matched-firm-adjusted return. The factors which affect the return include geographic expansion, broaden product line, increase market share, cash offer, tender offer, related acquisition, and multiple bidders. Ghosh (2001) usees employees to sales, operating expenses to sales, sales growth, and cash flow margin as measures and find no evidence that 
operating performance improves following acquisitions when using firms matched on performance and size as a benchmark.

Barkema and Schijven (2008) measure firm performance through ROA since ROA has been shown to be the least sensitive to biases due to changes in leverage or bargaining power caused by acquisitions. Kumar and Bansal (2008) measure the financial performance and check on five parameters to see the overall financial health of merging and acquiring companies. These five parameters are liquidity position, operating efficiency, overall efficiency, return to equity shareholders, and financing composition. The results indicate that in many cases of $M \& A$, the acquiring firms are able to generate synergy in long run that may be in the form of higher cash flow, more business, diversification, cost cuttings and so on. Zhu and Malhotra (2008) examine the short-term stock performance of a sample of Indian firms acquiring U.S. firms. It shows that Indian stock market reacts positively to the acquisition announcement, however, the positive abnormal return lasts for only three days. Afterward, the returns become negative.

Some scholars generalize some factors which might influence the performance after M\&A. King et al, 2004 conclude that the post-acquisition performance research has commonly examined the impact of four variables: whether the acquisition is made by a conglomerate firm, whether the acquisition is of a related firm, the method of payment (i.e., cash or equity) used for the acquisition, and whether the acquiring firm has prior acquisition experience. Leger and Quach (2009) examine factors which can affect the performance of M\&A and categorize these factors into macro (exchange rate, economic condition and culture difference), organization (prior acquisition experience, size of the organization and corporate governance structure), industry commonality (related-level and type of mergers and acquisitions) and characteristic of deal (the method of payment and how much the shares of the target firms).

\section{Diversification}

Based on the above studies, we can find that the industry commonality is often used to discuss the impact of mergers and acquisitions performance. If the acquiring and target firms are not related when making acquisitions, we can see it is the diversification strategy of acquiring firms. Malcolm and Wolf (1978) claim that when a company has the ability to export or import surplus skills or resources useful in its competitive environment, related diversification is an attractive strategic option. When a company possesses the skills and resources to analyze and manage the strategies of widely different businesses, unrelated diversification can be the best strategic option. Amihud and Lev (1981) infer that if managers are not properly diversified, they would diversify the holdings of the firm to reduce the risk even though diversification offers few benefits to shareholders. Donaldson and Lorsch (1983) conclude that managers would try to enter new lines of business to assure the survival and continuity of the firm even when shareholder wealth maximization dictates shrinkage or liquidation.

However, many theories consider the diversification would decrease the firm's value. Morck, Shleifer and Vishny (1990) demonstrate that the returns to acquiring shareholders are lower when their firm diversifies, when it buys a rapidly growing target, and when its managers performed poorly before the acquisition. Markides (1992) argues that if firms do much diversify, the cost of co-ordination between different businesses could increase and reduce the economy of scale. According to Jose and Simi (2002), firms that refocus their operations would have suffered a significant decrease in value if they had remained diversified.

\section{Industry Commonality}

Some studies investigate the definition of commonality. The commonality of acquired firms to their acquirers (where commonality is defined in terms of resource or product-market similarity) is often assumed to impact the post-acquisition performance of the acquiring firms (King et al, 2004). Seth (1990) proposes that diversification acquisition strategies differ essentially with regard to the degree of relatedness of the combining firms. Merging firms may be considered related when a common skill, resource, market, or purpose applies to each. That is, if they employ similar production techniques, serve similar markets and use similar distribution systems, and employ science-based research. According to the previous studies, we conclude that the relation between acquiring firm and target firm can also be categorized into two parts, related and unrelated. If acquiring firms and target firms have similar resources, markets and products, it is called related M\&A. If they are in different markets and do not compete directly, it is called unrelated M\&A.

Many scholars consider that there is a positive relation between the industry commonality and the performance of M\&A. Kusewitt (1985) provides some evidence that the degree of business commonality between acquiring and target firm is positively related to performance on the average. Acquisitions should be made in related businesses to enhance synergy and management effectiveness. Singh and Montgomery (1987) investigate the conceptual argument that acquisitions related in product/market or technological terms create higher value than unrelated acquisitions. Acquired firms in related acquisitions have substantially higher gains than acquired firms in unrelated acquisitions. These findings indicate that related target firms benefit more from acquisition than unrelated target firms. Shelton (1988) finds that business fits in which the assets of either the target or the bidder are used more intensively-identical, related-complementary and related-supplementary-create value. However, acquisitions that permit expansion into new markets or within the same business create the most value. If the purpose of takeover is to enter the new and highly relevant to the original industry, it is possible to create the greatest value. Healy (1992) provides the empirical result that the performance of related 
acquisitions is better than unrelated when he uses the operating cash flow as the indicator. Switzer (1996) follows the research method of Healy (1992) by increasing the sample and period numbers and obtains a consistent result with Healy (1992). Markides and Ittner (1994) evidence that the related acquisitions are positively associated with wealth creation in United States international acquisitions and related acquisitions create much more value than unrelated ones. Zantout (1996) indicates that abnormal returns to the shareholders of an acquiring firm are greater when the target operates in a related industry. This finding is the evidence that shareholders do not look favorably at diversification programs. They prefer a corporate strategy that exploits the commonality of the business units. According to Hitt, Harrison, and Ireland (2001), industry familiarity can eliminate or significantly diminish the need for acquiring firm managers to "learn" the business of the target firm, and facilitate learning from the acquisition process. Hagedoorn and Duysters (2002) demonstrate that compared with unrelated M\&As, related M\&As show superior economic performance because of synergetic affects that follow from economies of scale and scope. Frank (2004) finds that related construction mergers create wealth for shareholders of the target firms by examining the financial performance of UK construction companies, which have been involved in construction related M\&A on acquiring firms' and target firms' stock performance in the UK construction industry.

On the other hand, there are many opposite opinions on the relation between the industry commonality and the performance of mergers and acquisitions. Seth (1990) indicates that value is created in both unrelated and related acquisitions. Further, the data do not appear to indicate that related acquisitions create more value than unrelated acquisitions on average. Agrawal, Jaffe, and Mandelker (1992) analyze the impact of mergers and acquisitions on shareholder wealth and mentioned both the related and unrelated mergers and acquisitions cannot bring benefits to shareholders especially related acquisitions. Datta and Puia (1995) choose 112 cross-border M\&A cases which have significant cumulative abnormal returns in before and after the 15 days when they announce the news about cross-border M\&A. However, the impact of commonality on shareholder value creation is not clear. Flanagan (1996) does not support that acquiring firm's shareholders benefit more in purely relater acquisitions than in purely unrelated acquisitions by improving the classification of industries and including strategic fits between enterprises. Linn and Switzer (2001) use the return of cash flow before tax to evaluate the long-term performance after M\&A. It shows that the acquiring firm can benefit from M\&A, but is not sensitive to factors such as offer size, the commonality of bidder's and target's business, nor bidder leverage. Ghosh (2001) find that there is a significant relation between the methods of payment and commonality and the operating cash flow after acquisitions. In particular, the unrelated-acquisition can increase more operating cash flow.

According to above theories, I choose Kusewitt (1985) and Agrawal, Jaffe, and Mandelker (1992) which infer opposite views and use their methods to examine the relation between industry commonality and performance in the next section.

\section{The Methodology and Model}

\section{Sample and Data Selection}

The sample of the acquiring firms in this paper is from the period 1995 to 2009. The first step is gathered all mergers and acquisitions events during the study period from the Security Data Company (SDC). Second, we chose these acquiring firms which have the complete three years monthly return after the effective date of acquisitions and financial information from COMPUSTAT and CRSP. In addition, if one acquiring firm has more than one acquisition in three years, we only choose the first acquisition. We end up with the final sample of 3016.

As a result of the purpose of this paper is examining the influence of industry commonality on the post-performance after acquisitions, we classified 3016 acquisitions events as related and unrelated by their SIC code. Some relevance theories provide the criteria about differentiating industry commonality. Haunschild (1994) developed a measure of commonality that classified acquisitions as horizontal, related. An acquisition in which the acquiring firm's SIC code matched the acquired firm was classified as "horizontal" at the 4-digit level and "related" at the 2-digit level. Walker (2000) used the SIC code to classify the acquisition as related (i.e. the acquiring and target firms have the same primary two-digit SIC code) or unrelated.

Following the previous studies, if the acquiring and target firms have the same largest 2-digit SIC code, it was viewed as the related acquisitions. Then, the final sample is 3016 which consists of 1732 related and 1284 unrelated acquisitions. The selection process and acquisitions frequency distribution are shown in Table 1.

\section{Methodology}

According to previous researches, there are many different measures which are used to examine the firm's performance after the acquisition. Asquith (1983) analyzed the abnormal stock price performance of NYSE firms and displayed the negative abnormal returns after the acquisition over three years. However, others lack the consistent findings. Franks, Harris, and Titman (1991) do not show the significantly underperformance and conclude that previous findings of poor performance over three years after takeover are likely due to benchmark errors rather than mispricing at the time of the takeover. Based on these relevance theories, we used three years as the study period. In our first method, we have to use the market return to calculate the beta of acquiring firm, so we choose the monthly return that measuring the post-merger performance in this paper and a unit of period is one year.

In order to find the relation between post-merge 
performance of the acquiring firm and the industry commonality, we used two alternative methodologies to examine the post-merger performance.

\section{Model1:}

We use the methodology which following Dimson and Marsh (1986), Lakonishok and Vermaelen (1990) and Agrawal, Jaffe and Mandelker (1992) to examine the acquisition abnormal performance. They adjusted the both beta risk and market capitalization since the stock performance can be significantly affected by the beta risk and firm size in the short and long-term returns.

The adjustment of firm size and beta risk is setting the control group which has the same level with the samples in this paper. The size control groups are ranked all stocks which are from COMPUSTAT (North America) and CRSP by their market capitalization at the end of each year and allocated them to 10 decile portfolios. For beta risk, there is an assumption which each beta is the same when firms completed the acquisition.

$$
\varepsilon_{i, t}=R_{i, t}-R_{s, t}-\left(\beta_{i}-\beta_{s}\right)\left(R_{m, t}-R_{f, t}\right)
$$

where

$\varepsilon_{i, t}=$ the stock $i$ 's abnormal performance

$R_{i, t}=$ the return on stock $i$ over month $t$.

$R_{s, t}=$ the equally weighted average return during month $t$ on the control group of all firms in the same size decile as firm $i$, based on the market value of equity at the end of the previous year.

$\beta_{i}=$ the beta of security $i$. We estimated $\beta_{i}$ using monthly data over the period from month 1 to 36 after the acquisition completion.

$\beta_{s}=$ the beta of the control group. We estimated $\beta_{S}$ over months 1 to 36 which matched the completion month.

$R_{m, t}=$ the return on the market index. We used the S\&P composite index.

$R_{f, t}=$ the risk-free rate in month $t$, as measured by the one-month Treasury bill.

The average abnormal return (AAR) over all stocks in month $\mathrm{t}$ is:

$$
A A R_{t}=\frac{1}{N_{t}} \sum_{i=1}^{N_{t}} \varepsilon_{i t}
$$

where $N=$ the number of securities in the sample with a return in event month $t$.

The event period of this paper is month 1 to 36 , and we separated it into three periods which are 1 12, 13 24 and 25 36 month.

The cumulative average abnormal return (CAAR) from event month $t_{1}$ to $t_{2}$ is:

$$
C A A R_{t_{1}}^{t_{2}}=\sum_{t=t_{1}}^{t_{2}} A R R_{t}
$$

According to the months after merger completion, we could get two outcomes of ARR and examine whether these outcome are significant or not. Then, test statistics for abnormal return between related and unrelated events follow the Two-Sample T-test.

\section{Model2:}

Based on Kusewitt (1985), we use statistical analysis of historical data to measure the post-merger performance. In addition, we also control acquiring firm size, acquisition timing, organizational slack and duplicate acquisition events of acquiring firm which are influence on firms' performance.

$$
\begin{aligned}
R_{i, t}=\alpha+\beta_{1} \text { Dummy_relation }+\beta_{2} \text { Size } & \\
& +\beta_{3} \text { Dummy_acquisitions }+\beta_{4} \text { OS } \\
& +\beta_{5} \text { Timing }
\end{aligned}
$$

where

$R_{i, t}=$ the return on stock $i$ over month $t$

Dummy_relation $=$ the industry commonality

Size $=$ the firm size of acquiring firm.

Dummy_acquisitions $=$ the duplicate acquisitions of acquiring firm.

$O S=$ organization slack

Timing $=$ acquisition timing.

Dependent Variables: Firm Performance $\left(R_{i, t}\right)$

$R_{i, t}$ is the return on a stock $i$ over month t. We use the monthly return from CRSP

Independent Variables: Industry Commonality

(Dummy_relation)

If the acquiring and target firms have the same largest 2-digit SIC code, Dummy_relation is equal to one. If the acquiring and target firms do not have the same largest 2-digit SIC code, Dummy_relation is equal to zero.

Control Variables:

\section{Firm size (Size)}

Dimson and Marsh (1986) though firm size is an important factor which would influence the long-run performance. We measured the firm size by the total assets of the acquiring firm at the end of year before completion of the merger. Since the volatility of total assets is steeper which shown in Table 2, we adjust the extreme values to decreasing the heavily influence by Winsorize.

\section{Acquisitions events within three years}

\section{(Dummy_acquisitions)}

In order to rule out the interactive impact on stock return, we only chose the first event if any acquiring firm has several acquisitions events within three years. We define dummy as 1 if the acquiring firm has more than one acquisition event during the three years.

\section{Organizational slack $(O S)$}

Wan and Yiu (2009) suggested that organizational slack would improve firm performance and accentuate the positive relationship between corporate acquisitions and firm performance during an environmental jolt. It would have negative impact on firm performance and make the 
acquisition-performance relationship more negative before and after a jolt. Organizational slack is defined as a cushion of resources that allows an organization to adapt to internal or external pressures as well as to initiate changes in strategy in regard to the external environment. We form a measure of organizational slack using the ratio of the debt to equity at the end of year before completion of the merger.

\section{Acquisition timing (Timing)}

Followed the Kusewitt (1985), the market timing measure was found to be significantly negatively related to market return. The acquisition timing measure is the ratio of the Standard and Poor 500 average value for the third month prior to the effective date of acquisitions to the Standard and Poor trend value for that month. The trend was from monthly averages of this index from January 1995 through December 2009.

\section{The Findings}

\section{Abnormal Return}

First, we use the abnormal return to measure the post-merger performance and the sample includes 3016 mergers over 1995 2009. Results are shown in Table 3.

$$
\varepsilon_{i, t}=R_{i, t}-R_{s, t}-\left(\beta_{i}-\beta_{s}\right)\left(R_{m, t}-R_{f, t}\right)
$$

Where $R_{i, t}$ and $R_{s, t}$ are the monthly stocks returns on firm $i$ and its size control group ; $\beta_{i}$ and $\beta_{s}$ are betas measured over 36 months after merger; $R_{m, t}$ and $R_{f, t}$ are the return in month $\mathrm{t}$ on the $\mathrm{S} \& \mathrm{P}$ composite index and one-month Treasury bills.

First, we can observe all abnormal returns are negative for holding periods of one, two and three years. The result shows that both related and unrelated acquisitions cannot bring any excess return to acquiring firms. It is similar with Flanagan (1996) who though that both of related and unrelated show the negative abnormal returns. I note approximately $50 \%$ of acquisitions events have the positive abnormal return after merger completion. Although half of acquisitions have positive abnormal return, the negative impact is significantly larger than positive impact.

Second, we examine the performance of both related and unrelated for each period in our sample. We find that ARR has been the trending down over three years after completion. The abnormal returns of related acquisition are $-1.7 \%$, $-1.37 \%$ and $-5.01 \%$ during the three year and the unrelated acquisitions are $-1.21 \%,-8.24 \%$ and $-11.99 \%$. It implies that the negative impact of merger on performance is more significant in the long run. In addition, the CAARs for both groups of acquiring firms show negative performance $(-8.08 \%$ and $-21.45 \%)$ over the three years post-merger period.

The differences of related and unrelated acquisitions are $6.87 \%, 6.97 \%$ and $13.35 \%$ on the second, third AAR and Cumulative AAR which are significant with 0.0106, 0.0199 and 0.060 of P-value after merger completion. The industry commonality can affect the post-merger performance significantly, although both coefficients of them are negative. The related acquisitions are better than the unrelated acquisitions. As time goes on, the difference of ARR between related and unrelated become larger. It implies that the effect of industry commonality for acquiring firms is more significant in the long term.

In contrast with the same methodology which we follow Agrawal, Jaffe and Mandelker (1992), they found the related acquisition is worse than the unrelated acquisition. They considered the possibility that the related mergers were concentrated in poorly performing industries. Thus, it could explain the poor post-merger performance of acquiring firms in related mergers. We infer two reasons from the result. First, we choose acquisitions events from SDC which include all industries, it does not exist the problem of few industries. Another reason is that it is biased for they only have limited related mergers in their sample ( 79 related and 686 unrelated mergers) since they defined the related acquisitions by four-digit SIC code rather than largest 2-digit.

\section{Multivariate Regression}

Our second approach of examining the influence of industry commonality on post-merger performance is followed the Kuseitte (1985) and Wan and Yiu (2009) with considerations for firm size, acquisition timing and organization slack. For each month t relative to the month of completion, we estimate the following regression:

$$
\begin{aligned}
R_{i t}=\alpha+\beta_{1} \text { Dummy_relation }+\beta_{2} \text { Size } & \\
& +\beta_{3} \text { Dummy_acquisitions }+\beta_{4} \text { OS } \\
& +\beta_{5} \text { Timing }
\end{aligned}
$$

where $R_{i, t}$ is the return on an stock $\mathrm{i}$ over month $\mathrm{t}$; Dummy relation is the industry commonality which is defined by SCI code; Size_W is the total asset of acquiring and doing winsorize; Dummy_acquisitions is equal one if acquiring firm has duplicate acquisition; OS is the ratio of debt to equity; Timing is measured by S\&P 500 average value for the third month prior to the effective date of acquisitions to the Standard and Poor trend value. The sample includes 3016 mergers over 1995 2009.

As Table 4 shows, significantly positive relationships are found between industry commonality and market return ( $p$-value $<0.01$ ) over the second year, third year and average three years after merger completion. In agreement with Kusewitt (1985), Markides and Ittner (1994) and our original expectation, the return of related acquisitions are significantly higher than the unrelated and in accordance with the general M\&A theory which infer that diversification cannot produce increases in value.

No significant statistical relationships are found between the industry commonality and the performance at the first year after merger acquisition. We infer that is due to the temporary conflict between acquiring firm and target firms at the beginning of merger. After the internal integration, the related acquisitions generate the synergy for acquiring firms. Industry commonality is significantly positive related to the post-merger performance. The relationship between related 
and unrelated acquisitions is the consistent in two results in spite of using the different method to measure other variables which can affect the performance. The related acquisition is more profitable for acquiring firms than unrelated acquisitions.

Analysis indicates significant and negative relationships between the adjusted firm size and market return $(\mathrm{p}<0.01)$. We infer that the large acquiring firms need more efforts and time to integrate the organization after mergers so it is difficult for the stock price of large acquiring firms to increase significantly since the only one transaction.

Organizational slack is no significantly related to the performance. Based on Wan and Yiu (2009), the organization slack has the impact on the relationship between acquisitions and firm performance during or before and after an environment jolt. Owing to the long study period of this paper, the impact of organization slack on performance does not exist.

It is not significant negative relationships between duplicate acquisitions and market return. About 57\% of the samples have more than one acquisition within the three year. The result implies that it is uncertain for the firm to make profits when adopts more acquisitions. It proves the result of our first method that the acquisition cannot bring any abnormal return for acquiring firm.

The market timing measure is found to be significantly negatively related to market return $(\mathrm{p}<0.0001)$. It shows that acquiring firms' stock would benefit more from market highs because of larger price/earnings multiples during these periods than from the target firms. The result is same with the Kusewitt (1985).

\section{Summary and Conclusions}

This study examines the relation between the industry commonality and post-merge performance of firms and use two different methods. The result for a sample of 3016 acquisitions indicates that the industry commonality between acquiring and target firms is significantly related to the post-merge performance of acquiring firms. According to two measures and taking different variables into account, we obtain the consistent result.

First, the measure of abnormal return adjusts the firm size and beta risk by using the control group. Although the abnormal returns of acquisitions during three years are negative, the abnormal return of related acquisitions is significantly better than unrelated acquisitions. The outcome implies that both related and unrelated acquisitions do not have abnormal return. Perhaps companies should do more evaluating before mergers or consider another way to achieve the same target.

Second, we run the regression and control organization slack, firm size, market timing and duplicate acquisitions which significantly affect the post-merger performance. The related acquisitions have significantly positive relation with market performance in the second and third years.

Our results are consistent with the explanations offered by Kusewitt (1985) and Markides and Ittner (1994) for that the significant relationship between industry commonality and post-merge performance. In addition, we observe the related effect is more significant after one year of merger completion. It concludes that the impact of industry commonality on post-merger performance for acquiring firms is significant in the long run. A future research can continue and try to find out which industry is affected most by industry commonality when the mergers happen.

\section{Appendix}

Table 1. Sample Selection Process

\begin{tabular}{|c|c|c|c|c|}
\hline Year & Acquisitions from SDC & Completed market and financial information & Related & Unrelated \\
\hline 1995 & 28,558 & 131 & 75 & 56 \\
\hline 1996 & 30,053 & 139 & 76 & 63 \\
\hline 1997 & 30,798 & 123 & 73 & 50 \\
\hline 1998 & 35,866 & 223 & 120 & 103 \\
\hline 1999 & 39,106 & 193 & 110 & 83 \\
\hline 2000 & 43,615 & 197 & 110 & 87 \\
\hline 2001 & 34,051 & 38 & 24 & 14 \\
\hline 2002 & 29,859 & 284 & 159 & 125 \\
\hline 2003 & 32,925 & 281 & 158 & 123 \\
\hline 2004 & 35,250 & 204 & 128 & 76 \\
\hline 2005 & 38,451 & 260 & 144 & 116 \\
\hline 2006 & 44,205 & 277 & 170 & 107 \\
\hline 2007 & 51,107 & 264 & 153 & 111 \\
\hline 2008 & 50,357 & 235 & 144 & 91 \\
\hline 2009 & 45,954 & 167 & 88 & 79 \\
\hline Total & 541,97 & 3,016 & 1732 & 1284 \\
\hline
\end{tabular}


Table 2. Descriptive Statistics of Variables

\begin{tabular}{|c|c|c|c|c|}
\hline Variable & Mean & Std. Dev. & Min & Max \\
\hline Firm Performance $\left(R_{i, t}\right)$ & 1.024424 & 14.08286 & -86.65339 & 275 \\
\hline Industry Commonality (Dummy_relation) & 0.574271 & -0.4944554 & 0 & 1 \\
\hline Firm size (SIZE) & 20839.44 & 122150.5 & .817 & 3510975 \\
\hline $\begin{array}{c}\text { Acquisitions events within three years } \\
\text { (Dummy_acquisitions) }\end{array}$ & 0.570623 & 0.4949895 & 0 & 1 \\
\hline Organizational slack (OS) & 2.288674 & 16.49251 & -689.679 & 263.272 \\
\hline Acquisition timing (Timing) & .9448893 & 7.612753 & -28.6179 & 16.33716 \\
\hline
\end{tabular}

Note: $R_{i, t}=$ the return on stock $i$ over month $t$; Dummy_relation=the industry commonality; Size $=$ the firm size of acquiring firm; Dummy_acquisitions $=$ the duplicate acquisitions of acquiring firm; $O S=$ organization slack; Timing = acquisition timing.

Table 3. Post-Merger Performance of Acquiring Firms after Adjustment for Firm Size and Beta Risk

\begin{tabular}{|c|c|c|c|c|}
\hline \multirow{2}{*}{$\begin{array}{c}\text { Months After } \\
\text { Merger Completion }\end{array}$} & \multicolumn{2}{|c|}{ Average Abnormal Return } & \multirow[b]{2}{*}{ Difference } & \multirow{2}{*}{$\begin{array}{l}\text { Percent of Positive abnormal } \\
\text { return }\end{array}$} \\
\hline & $\begin{array}{c}\text { Related } \\
(\mathrm{N}=1732)\end{array}$ & $\begin{array}{l}\text { Unrelated } \\
(\mathrm{N}=1284)\end{array}$ & & \\
\hline $1 \sim 12$ & $-1.70 \%$ & $-1.21 \%$ & $\begin{array}{c}-0.49 \% \\
(0.858836) \\
\end{array}$ & $50.23 \%$ \\
\hline $13 \sim 24$ & $-1.37 \%$ & $-8.24 \%$ & $\begin{array}{c}6.87 \% \\
\left(0.010610^{* *}\right)\end{array}$ & $52.54 \%$ \\
\hline $25 \sim 36$ & $-5.01 \%$ & $-11.99 \%$ & $\begin{array}{c}6.97 \% \\
\left(0.019957^{* *}\right)\end{array}$ & $49.08 \%$ \\
\hline Cumulative AAR & $-8.08 \%$ & $-21.45 \%$ & $\begin{array}{c}13.35 \% \\
\left(0.060636^{*}\right)\end{array}$ & $52.83 \%$ \\
\hline
\end{tabular}

Note: $t$ statistics in parentheses $,{ }^{*} p<0.1,{ }^{* *} p<0.05,{ }^{* * *} p<0.01$

Table 4. Regression of Market Return

\begin{tabular}{|c|c|c|c|c|}
\hline \multirow[b]{2}{*}{ Rit } & \multicolumn{4}{|c|}{ Months After Merger Completion } \\
\hline & $1-36$ & $1-12$ & $13-24$ & $25-36$ \\
\hline intercept & $\begin{array}{c}0.943 \\
\left(10.86^{* * *}\right)\end{array}$ & $\begin{array}{c}1.239 \\
\left(8.16^{* * *}\right)\end{array}$ & $\begin{array}{c}0.788 \\
\left(5.29^{* * *}\right)\end{array}$ & $\begin{array}{c}0.800 \\
\left(5.34^{* * *}\right)\end{array}$ \\
\hline Dummy_relation & $\begin{array}{c}0.288 \\
\left(3.35^{* * *}\right)\end{array}$ & $\begin{array}{c}-0.0917 \\
(-0.62)\end{array}$ & $\begin{array}{c}0.516 \\
\left(3.47^{* * *}\right)\end{array}$ & $\begin{array}{c}0.439 \\
\left(2.93^{* * *}\right)\end{array}$ \\
\hline Size_W & $\begin{array}{c}-0.00000315 \\
\left(-4.56^{* * *}\right)\end{array}$ & $\begin{array}{c}-0.00000279 \\
\left(-2.53^{* *}\right)\end{array}$ & $\begin{array}{c}-0.00000250 \\
\left(-2.23^{* *}\right)\end{array}$ & $\begin{array}{c}-0.00000415 \\
\left(-3.09^{* * *}\right)\end{array}$ \\
\hline Dummy_acquisitions & $\begin{array}{c}-0.0348 \\
(-0.39)\end{array}$ & $\begin{array}{l}0.198 \\
(1.31)\end{array}$ & $\begin{array}{c}0.0957 \\
(0.62)\end{array}$ & $\begin{array}{c}-0.398 \\
\left(-2.57^{* *}\right)\end{array}$ \\
\hline OS & $\begin{array}{c}0.000887 \\
(0.40)\end{array}$ & $\begin{array}{c}-0.00223 \\
(-0.47) \\
\end{array}$ & $\begin{array}{c}0.00154 \\
(0.49) \\
\end{array}$ & $\begin{array}{c}0.00335 \\
(1.01)\end{array}$ \\
\hline Timing & $\begin{array}{c}-0.0193 \\
\left(-3.33^{* * *}\right)\end{array}$ & $\begin{array}{c}-0.0464 \\
\left(-4.33^{* * *}\right)\end{array}$ & $\begin{array}{c}-0.0173^{*} \\
(-1.77) \\
\end{array}$ & $\begin{array}{c}0.00590 \\
(0.62)\end{array}$ \\
\hline Adjusted $\mathbf{R}^{2}$ & 0.062 & 0.062 & 0.061 & 0.062 \\
\hline
\end{tabular}

Note:

1. $t$ statistics in parentheses ${ }^{*} p<0.1,{ }^{* *} p<0.05,{ }^{* * *} p<0.01$

2. $R_{i, t}=$ the return on stock $i$ over month $t$; Dummy_relation $=$ the industry commonality; Size $=$ the firm size of acquiring firm; Dummy_acquisitions $=$ the duplicate acquisitions of acquiring firm; $O S=$ organization slack; Timing = acquisition timing.

\section{REFERENCES}

[1] Kusewitt, J. B., 1985, 'An exploratory study of strategic acquisition factors relating to performance', Strategic Management Journal, vol. 6, no. 2, pp. 151-169.

[2] Healy, P.M., K.G. Palepu, and R.S. Ruback, 1992, 'Does corporate performance improve after mergers', Journal of Financial Economics, vol. 31, no. 2, pp. 135-175.

[3] Switzer, J. A., 1996, 'Evidence on real gains in corporate acquisitions', Journal of Economics and Business, 48(5), 443-460.

[4] Constantinos C. Markides and Christopher D. Ittner 1994, 'Shareholder Benefits from Corporate International Diversification: Evidence from U.S. International Acquisitions', Journal of International Business Studies, vol. 25, no. 2, pp.343-366.

[5] Linn, S. C. and J. A. Switzer, 2001, 'Are cash acquisitions associated with better postcombination operating performance than stock acquisition', Journal of Banking and Finance, vol. 25, no. 6, pp. 1113-1138.

[6] Huang, J. 2009, 'A Research on the Influences of 
Transnational Merger and Acquisition on China's Industry Security', International Journal of Business and Management, 4(4), 77.

[7] Ghosh, A. 2001, 'Does operating performance really improve following corporate acquisitions', Journal of Corporate Finance, vol. 7, no. 2, pp. 151-178.

[8] Seth, A., 1990, 'Value creation in acquisitions: a reexamination of performance issues', Strategic Management Journal, vol. 11, pp. 99-115.

[9] Fowler, K. L. and D. R. Schmidt, 1989, 'Determinants of tender offer post-acquisition financial performance', Strategic Management Journal, vol. 10, no. 4, pp. 339-350.

[10] Agrawal, A., J. Jaffe, and G. Mandelker, 1992, 'The post-merger performance of acquiring firms: a re-examination of an anomaly', Journal of Finance, vol. 47, pp.1605-1621.

[11] Bruton, G. D., B. M. Ovlatt and M. A. White 1994, 'Performance of acquisitions of distressed firms', Academy of Management Journal, vol. 37, no. 4, pp. 972-989.

[12] Ooghe, H. and S. Balcaen, 2000, 'De financiële toestand van de Belgische ondernemingen: sleutelratio's en risico-indicatoren 1991-1999', Diegem: Kluwer/Ced.Samson

[13] Walker M. M., 2000, 'Corporate takeovers, strategic objectives, and acquiring-firm shareholder wealth', Financial Management, vol. 29, no. 1, pp. 53-66

[14] Barkema, H. G. and M. Schjven 2008, 'Toward unlocking the full potential of acquisitions: the role of organizational restructuring', Academy of Management Journal, vol. 51, no. 4, pp. 696-722.

[15] Kumar, S. and L. K. Bansal, 2008, 'The impact of mergers and acquisitions on corporate performance in India', Management Decision, vol. 48, no. 10, pp. 1531-1543.

[16] Zhu, P. C. and S. Malhotra, 2008, 'Announcement effect and price pressure: an empirical study of cross-border acquisitions by Indian firms', International Research Journal of Finance and Economics, vol. 13, no. 1, pp. 24-41.

[17] King, D. R., D. R. Dalton, C. M. Daily, and J. G. Covin, 2004, 'Meta-analyses of post-acquisition performance: indications of unidentified moderators', Strategic Management Journal, vol. 25 , pp. 187-200.

[18] Leger, P. M. and L. Quach, 2009, 'Post-merger performance in the software industry: The impact of characteristics of the software product portfolio', Technovation, vol. 29, no. 10, pp.704-713.

[19] Salter, M. S. and W. A. Weinhold 1978, 'Diversification via acquisition: creating value ', Harvard Business Review.

[20] Amihud Y, Lev B, 1981, 'Risk reduction as a managerial motive for conglomerate mergers', Bell Journal of Economics 12: 605-617.

[21] Donaldson, G. and J. Lorsch, 1983, 'Decision Making at the Top', Basic Books, New York.

[22] Shleifer, A., Vishny, R., \& Morck, R., 1987, 'Characteristics of hostile and friendly takeover targets', Center for Research in Security Prices, Graduate School of Business, University of Chicago.

[23] Markides, C. C., 1992, 'Consequences of corporate refocusing: Ex ante evidence', Academy of Management journal, 35(2), 398-412.

[24] Campa, J. M., \& Kedia, S., 2002, 'Explaining the diversification discount', The Journal of Finance, 57(4), 1731-1762.

[25] Singh, H., \& Montgomery, C. A., 1987, 'Corporate acquisition strategies and economic performance', Strategic Management Journal, 8(4), 377-386.

[26] Shelton, L. M., 1988, 'Strategic business fits and corporate acquisition: Empirical evidence', Strategic Management Journal, 9(3), 279-287.

[27] Zantout, Z. Z., \& O'Reilly-Allen, M., 1996., 'Determinants of corporate strategy and gains of acquiring firms', Journal of Accounting, Auditing \& Finance, 11(1), 119-129.

[28] Hitt, M. A., Harrison, J. S., \& Ireland, R. D., 2001, 'Mergers \& acquisitions: A guide to creating value for stakeholders', Oxford University Press.

[29] Hagedoorn, J., \& Duysters, G., 2002, 'The effect of mergers and acquisitions on the technological performance of companies in a high-tech environment', Technology Analysis \& Strategic Management, 14(1), 67-85.

[30] Delaney, F. T., \& Wamuziri, S. C., 2004, 'The impact of mergers and acquisitions on shareholder wealth in the UK construction industry', Engineering, Construction and Architectural Management, 11(1), 65-73.

[31] Datta, D. K., \& Puia, G., 1995, 'Cross-border acquisitions: An examination of the influence of relatedness and cultural fit on shareholder value creation in US acquiring firms', MIR: Management International Review, 337-359.

[32] Flanagan, D. J., 1996, 'Announcements of purely related and purely unrelated mergers and shareholder returns: Reconciling the relatedness paradox', Journal of Management, 22(6), 823-835.

[33] Haunschild, P. R., 1994, 'How much is that company worth? : Interorganization relationships, uncertainty and acquisition premiums', Working paper. University of Wisconsin-Madison.

[34] Asquith, P., 1983, 'Merger bids, uncertainty and stockholder returns', Journal of Financial Economics, vol. 11, pp. 51-83.

[35] Franks, J. R., R. S. Harris, and S. Titman, 1991, 'The post-merger share price performance of acquiring firms', Journal of Financial Economics, vol. 29, pp. 81-96.

[36] Dimson, E. and P. Marsh, 1986, 'Event study methodologies and the size effect: The case of UK Press recommendations', Journal of Financial Economics, vol. 17, pp. 113-142.

[37] Lakonishok, J. and T. Vermaelen, 1990, 'Anomalous price behavior around repurchase tender offers', Journal of Finance, vol. 45, pp. 455-477.

[38] Wan, W. P. and D. W. Yiu 2009, 'From crisis to opportunity: Environmental jolt, corporate acquisitions, and firm performance', Strategic Management Journal, vol. 30, pp. 791-801. 